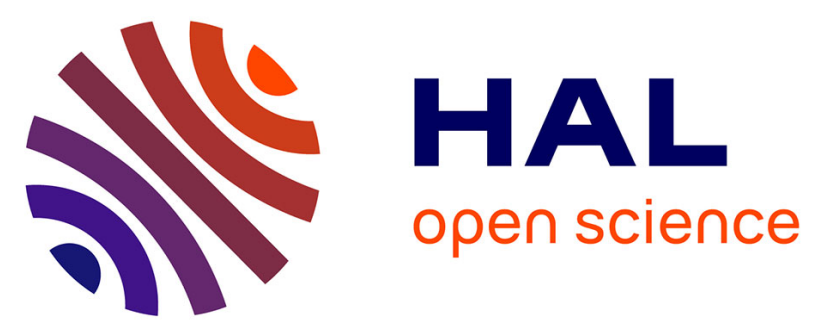

\title{
Evaluation of the acoustic emission 3D localisation accuracy for the mechanical damage monitoring in concrete
}

\author{
Antoine Boniface, Jacqueline Saliba, Zoubir Medhi Sbartaï, Narintsoa
} Ranaivomanana, Jean-Paul Balayssac

\section{To cite this version:}

Antoine Boniface, Jacqueline Saliba, Zoubir Medhi Sbartaï, Narintsoa Ranaivomanana, JeanPaul Balayssac. Evaluation of the acoustic emission 3D localisation accuracy for the mechanical damage monitoring in concrete. Engineering Fracture Mechanics, 2020, 223, pp.106742. 10.1016/j.engfracmech.2019.106742 . hal-02444538

\section{HAL Id: hal-02444538 \\ https://hal.science/hal-02444538}

Submitted on 27 Apr 2021

HAL is a multi-disciplinary open access archive for the deposit and dissemination of scientific research documents, whether they are published or not. The documents may come from teaching and research institutions in France or abroad, or from public or private research centers.
L'archive ouverte pluridisciplinaire HAL, est destinée au dépôt et à la diffusion de documents scientifiques de niveau recherche, publiés ou non, émanant des établissements d'enseignement et de recherche français ou étrangers, des laboratoires publics ou privés. 


\title{
Evaluation of the acoustic emission 3D localisation accuracy for the mechanical damage monitoring in concrete
}

\author{
Antoine Boniface ${ }^{\mathrm{a}}$, Jacqueline Saliba ${ }^{\mathrm{a}}$, Zoubir Mehdi Sbartai ${ }^{\mathrm{a}, *}$, \\ Narintsoa Ranaivomanana ${ }^{\mathrm{b}}$, Jean-Paul Balayssac ${ }^{\mathrm{b}}$ \\ ${ }^{a}$ I2M Laboratory, Civil Engineering Department, University of Bordeaux, France \\ ${ }^{\mathrm{b}}$ LMDC, INSA/UPS Génie Civil, 135 Avenue de Rangueil, 31077 Toulouse cedex 04, France
}

One of the main interests of the Acoustic Emission (AE) technique is its capability to detect and localise damage in structures. In this paper, the accuracy of AE sources localisation in concrete is studied. Several methods related to the choice of the onset detection of $\mathrm{AE}$ signals and to the location algorithm are evaluated and compared. The results show an important influence of the onset detection method on the location accuracy of AE events. The choice of the minimisation algorithm depends on the desired accuracy and the computation time. A statistical analysis based on the distribution of $\mathrm{AE}$ events and energy is presented for the detection of damages and the monitoring of the crack propagation. The comparison of the presented methodology demonstrates comparative results with Digital Image Correlation (DIC).

\section{Introduction}

The monitoring of concrete structures is a major concern in the field of civil engineering to ensure their durability and safety. In order to ensure these functions, the detection and the evaluation of damage severity is important to estimate its consequences on the residual life of the structure [1]. In the case of quasi-brittle material such as concrete, macro-cracks occur after the development of a micro-cracked area called fracture process zone (FPZ) [2-6]. Accumulation of micro-cracks causes a local decrease of the mechanical characteristics of the material leading to crack propagation [7].

Micro-cracking is a phenomenon of localized damage causing the release of mechanical energy resulting in the propagation of an elastic wave in the material radially from the source (called also event). The acoustic emission (AE) technique enables the detection of vibrations due to elastic wave propagation by piezoelectric sensors located on the material surface. The main interest of the AE technique is that it allows the monitoring of damage continuously. Some analysis based on signals parameters like energy give informations on the state of fracture [8-10]. It also allows, through the analysis of wave's arrival time and triangulation, the location of events. In this context, many localisation techniques and picking of arrival time criteria have been developed or adapted from seismic analysis [11-14]. Despite the large amount of localisation strategies in the literature, there is no consensus on a specific technique in concrete. This is mainly due to few comparative studies between those techniques and no quantitative evaluation of the

Abbreviations: AE, Acoustic Emission; AET, acoustic emission testing; FPZ, fracture process zone; FT, fixed threshold; AIC, Akaike Information Criterion; CMOD, crack mouth-opening displacement; GBNM, globalized and bounded Nelder-Mead algorithm; GA, genetic algorithm; AMA, adaptative meshing algorithm

* Corresponding author.

E-mail address: zoubir-mehdi.sbartai@u-bordeaux.fr (Z.M. Sbartaii). 
influence of localisation strategies on the quality of the results.

The characterization of the FPZ was studied in the literature based on different techniques as the scanning electron microscopy, the X-rays, the digital image correlation [15] and more particularly on the AE localisation map by considering different criteria as the AE energy or the AE events density [16]. However, this characterisation is dependent on the accuracy of the AE event localisation. The accuracy of localisation depends on many assumptions such as the wave velocity, the material properties, the media geometry, the sensors installation and coupling $[17,18]$. In addition, a loss or partial acquisition of AE signals can decrease the accuracy of AE monitoring in function of the adopted triggered acquisition modality [19]. The AE tomography and models taking into account a variable velocity have been also applied for a better imaging of damage [20-22]. In plate like structures, several techniques such as wavelet analysis and Newton based optimisation techniques have been used to determine the AE source location and velocity [23-27].

An important criterion for performing a good location is the picking of arrival times from the recorded AE signals [13,14]. In fact, the triangulation method is based on the detection of delays of AE signals between sensors. In order to overcome the errors generated by a fixed threshold (FT) method [28], several onset picking techniques have been proposed in the literature such as cross-correlation, autocorrelation, thresholding, and wavelet transforms [29-31]. The manual picking technique is very time consuming and not useful when dealing with high amount of data. The amplitude threshold picker (fixed or floating threshold) is widely used for its simplicity but may be source of error. The STA/LTA picker (Short Term Average/Long Term Average) and the automatic onset detection algorithms based on the Hinckley criterion and Akaike Information Criterion (AIC) are developed for a more accurate localisation of sources $[13,29,30]$. New methods based on analyses in the time domain and the time frequency domain have been also proposed as time-varying and continuous wavelet transform correlation methods [32,33].

The localisation process depends on the source localisation methods [34,35] and also on the resolution of the minimisation problem [36,37]. Several iterative algorithms, which consist in generating a sequence of testing and updating of a trial solution based on a linear least-squares algorithm, have been applied to obtain the optimal source location coordinates [38]. Simplex algorithm is a common algorithm used for its speed [39]. However, this algorithm converges to a local minimum in the minimisation problem and may lead, in some cases, to an incorrect solution. Algebraic approaches such as the Geiger iterative algorithm and the Bancroft direct algorithm, widely used in seismology, have also been successfully applied [40,41]. Artificial intelligent techniques have also been used for AE location as artificial neural network, Bayesian statistics and genetic algorithms [42,43]. Mapping is an alternative approach for the AE source location where, the arrival time differences are compared with those of a spatial coordinate system, i.e. a particular grid with variable fineness $[44,45]$.

In this paper, an experimental investigation is proposed to study concrete mechanical damages. Three point bending tests have been carried out on notched concrete beams and the monitoring of damage has been assessed by means of the $\mathrm{AE}$ technique in $3 \mathrm{D}$ configuration. In order to ensure a reliable location of micro-cracks, various methods of onset detection of AE signal and minimisation problem have been tested and their influence on the location map have been analysed. The first part of the following work is to highlight the influence of picking methods on the location. Subsequently, three alternative algorithms are developed to overcome the weaknesses of simplex algorithm, commonly used in the resolution of the location problem. The advantages and disadvantages of those methods and the possibility of improving the accuracy of AE technique are discussed. Finally, the most accurate methods have been used for mapping the events and energy distribution, and the crack propagation that has been validated by Digital Image Correlation (DIC).

\section{Experimental program}

\subsection{Materials and procedures}

The tested concrete is made with $52.5 \mathrm{R}$ Portland cement and crushed limestone aggregate. The composition of the concrete is shown in Table 1. The compressive strength at 28 days is about $47 \mathrm{MPa}$.

The tested concrete beams are $500 \mathrm{~mm}$ in length, $250 \mathrm{~mm}$ in height and $120 \mathrm{~mm}$ in width. A central notch having a width of $4 \mathrm{~mm}$ and a height of $10 \mathrm{~mm}$ is located at the bottom part of the beams (Fig. 1). The three-point bending test was performed using a hydraulic machine MTS of $100 \mathrm{kN}$ capacity (Fig. 1). The loading of the beam was conducted with a constant crack mouth-opening displacement (CMOD) rate of $2 \mu \mathrm{m} \mathrm{min}^{-1}$. The CMOD measurement consists in recording the distance between two alumina plates glued on the bottom surface of the beam, on each side of the notch with MTS Model 632.03F-30 clip gauge extensometer (range $\pm 4 \mathrm{~mm}$ ).

Table 1

Concrete composition.

\begin{tabular}{ll}
\hline Components & Mass proportions $\left(\mathrm{kg} \mathrm{m}^{-3}\right)$ \\
\hline Cement CEM I 52.5 CE NF & 320.0 \\
Water & 197.5 \\
Sand 0-4 mm & 830.0 \\
Aggregates 4-11 mm & 445.0 \\
Coarse aggregates 8-16 mm Balloy & 550.0 \\
\hline
\end{tabular}



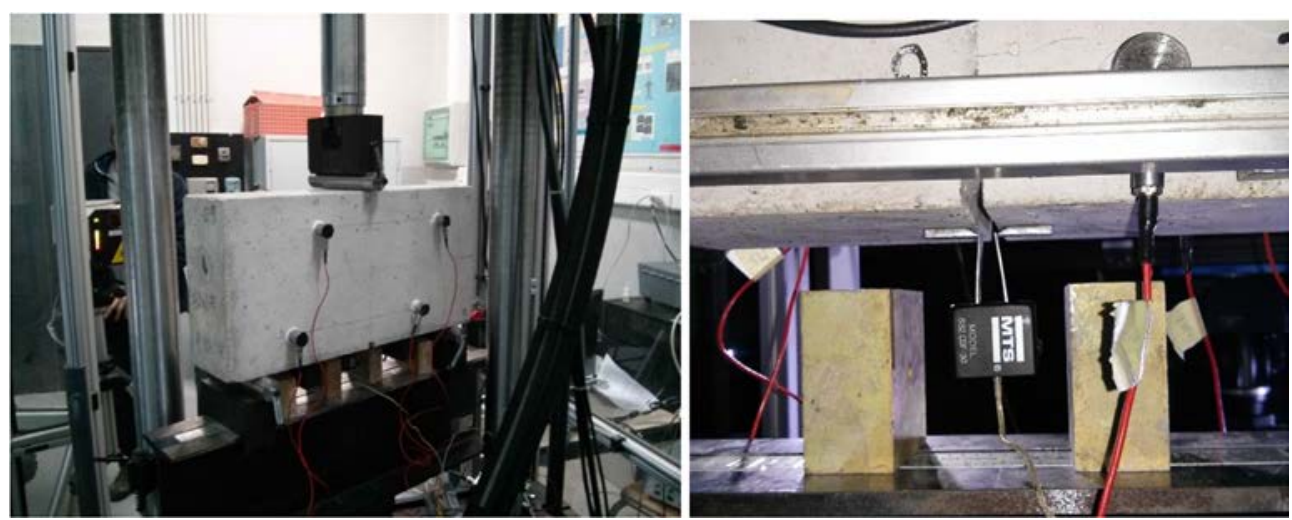

Fig. 1. Three point bending test on concrete beam (a). MTS CMOD device (b).

\subsection{Acoustic emission measurements}

The monitoring of damage was carried out using a network of 8 piezoelectric R15 sensors with a resonance frequency of $150 \mathrm{kHz}$. Transducers were placed around the expected location of the crack propagation. The two main faces of the beams were instrumented with 4 sensors to obtain a 3D localisation of AE events (Fig. 2). They were placed with silicon grease used as the coupling agent.

A sampling frequency of $1 \mathrm{MHz}$ was used for the acquisition of 2048 samples per AE signal. AE signals were amplified with a $40 \mathrm{~dB}$ gain amplifier. The signals are converted by a PCI-card 8 and filtered by a low pass filter of $400 \mathrm{kHz}$ and a high pass filter of $100 \mathrm{kHz}$. The signal detection threshold was set at a value of $35 \mathrm{~dB}$ based on noise measurement. The velocity was measured with the evaluation of time of flight pulses between sensors placed on each side of the beam Acoustic events are formed from a set of signals (or hits) received in a maximal period of $71 \mu$ s and by at least 4 sensors for a 3D source localisation.

\subsection{Digital image correlation}

The DIC system has been used to measure the displacement fields and to identify the appearance of cracks on the concrete surface. The displacement field is obtained by analysing the correlation between an image of the deformed specimen taken at a given time to a reference image, generally taken at the beginning of the test. Two cameras were linked with a stereovision technique in order to measure the displacement field in three dimensions by using two corresponding images. The third dimension is obtained during specimen deformation by stereo correspondence [46-49], or triangulation of two images that have a common part in their field.

The resolution of the system directly depends on the distribution of gray levels which in turn depends on the light intensity and the surface texture of the material. A sufficiently random speckle pattern has been realised on the studied concrete surface. White paint has been first applied at the surface before the black speckle to obtain better contrast. Two lamps were used to improve the luminosity of the images. Two 5.0 MP numerical cameras have been used to obtain more stable pictures without any vibration. The images with $2128 \times 564$ pixels were stored in the system and were analysed afterwards using Vic3D software v7.2.4. During the post treatment analysis, every zone of interest of the image is divided into several finite subsets. The resolutions obtained for each size of specimen were 1 pixel $=105 \mu \mathrm{m}$. The chosen size of one subset is $19 \times 19$ pixels in this case. The uncertainty of displacement field is about $6 \mu \mathrm{m}$.

\section{Localisation principle}

The location of micro-cracks is based on the following assumptions:

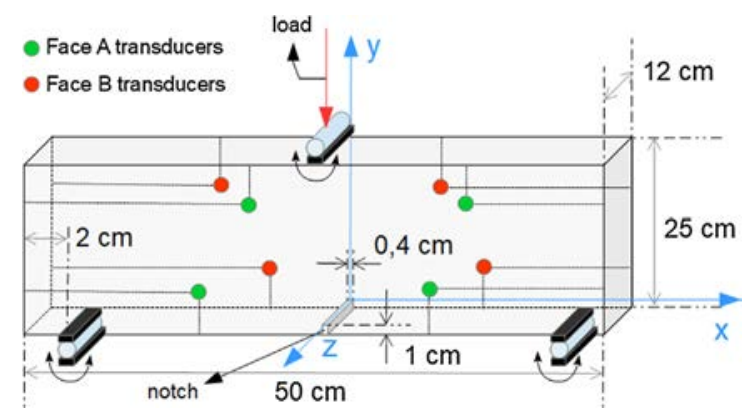

Fig. 2. Specimen geometry and AE transducers positions on two opposite faces A and B. 
- sources are punctual (called also event),

- sources are temporally spaced apart from each other so that the acoustic activity resulting from a source does not interfere with the acoustic activity of the next source,

- wave propagation velocity is constant,

- material is homogeneous and isotropic.

According to these hypothesis, waves travel from a source point to sensors following a straight path with a constant velocity.

$\mathrm{x}, \mathrm{y}, \mathrm{z}$ are the source location coordinate; $\mathrm{T}_{\mathrm{i}}(\mathrm{i}=1,2, \ldots, \mathrm{n})$ is the $\mathrm{i}_{\text {th }}$ piezoelectric transducer and its coordinate is $\left(\mathrm{x}_{\mathrm{i}}, \mathrm{y}_{\mathrm{i}}, \mathrm{z}_{\mathrm{i}}\right)(\mathrm{i}=1$, $2, \ldots, n) ; l_{i}(i=1,2, \ldots, n)$ is the distance from the source to the transducer $T_{i} ; t_{i}(i=1,2, \ldots, n)$ is the arrival time recorded by the transducer; $t_{0}$ is the origin time of AE source. $t_{i}$ can be expressed as:

$$
t_{i}=\frac{l_{i}}{v}+t_{0}
$$

where $\mathrm{v}$ is the wave velocity and $l_{i}=\sqrt{\left(x_{i}-x\right)^{2}+\left(y_{i}-y\right)^{2}+\left(z_{i}-z\right)^{2}}$, thus:

$$
\left(t_{i}-t_{0}\right) \times v=\sqrt{\left(x_{i}-x\right)^{2}+\left(y_{i}-y\right)^{2}+\left(z_{i}-z\right)^{2}}
$$

As seen in the previous parts, the localisation process is based on the measured arrival time of signals $t_{i}^{\text {meas }}$. Due to the lack of knowledge of the exact time when the source appeared, delays are considered relative to the first detected hit: $\Delta t_{i}^{\text {meas }}=t_{i}^{\text {meas }}-t_{1}^{\text {meas }}$. Considering previous assumptions, the delays between sensors depend on the position of the source. The location of events is thus determined by solving an error minimization problem between the recorded data via the sensors and an estimated event with a known position (Eq. (3)).

$$
\zeta=\sum_{i=1}^{n} \frac{\left(\Delta t_{i}^{\text {meas }}-\Delta t_{i}^{\text {esti }}\right)^{2}}{n}
$$

where " $n$ " is the number of sensors associated to the event.

The position of estimated events is determined by an iterative algorithm. The retained position corresponds to that of the estimated event for which the error criterion is minimum (Fig. 3).

Fig. 4 gives an overview of the shape of the error criterion (from Eq. (3)) in 3D for our beam geometry. This map has been obtained by the computation of all " $\zeta$ "inside the beam between a simulated source (in green) and more than 12 million estimated sources. $\zeta$ has a maximum value around the sensors and a minimum value at the source point. The goal of the minimisation algorithms is to find this minimum which corresponds to the position of the source. This map has been obtained in $3.7 \mathrm{~s}$ for one source. Regarding all events recorded during a test $(\sim 15,000)$, it would take more than $15 \mathrm{~h}$ of computation to obtain this map for all events. Note here that the computation time increases with the increase of specimen size.

To summarize, the localisation of $\mathrm{AE}$ events depends on at least three factors:

- the wave velocity,

- the capability to determine precisely the onset time of AE signals,

- the algorithm used to solve the minimisation problem.

In the following parts, the influence of picking methods and algorithms will be studied and discussed.

\subsection{Onset time detection methods}

\subsubsection{Fixed threshold (FT)}

The determination of the onset time of AE signals has been identified as a source of error for events location. In fact, the overall

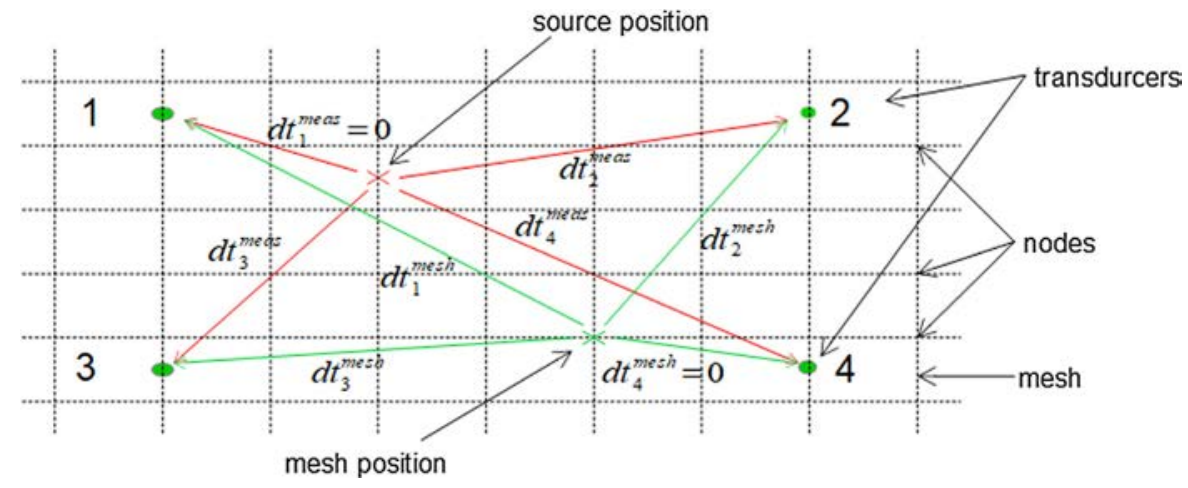

Fig. 3. Principal of AE events location by AE technique. 


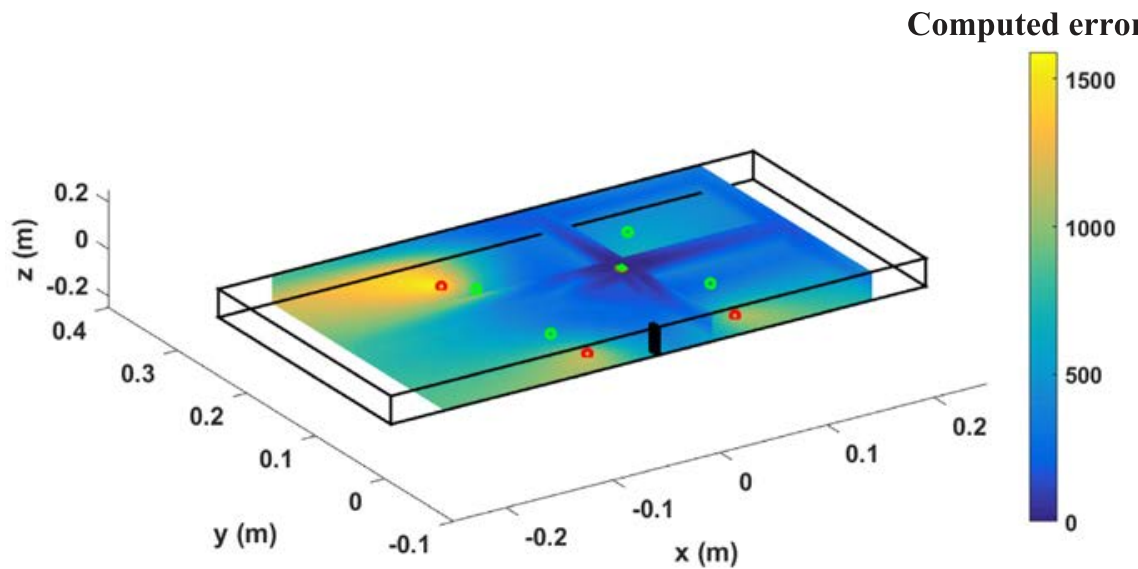

Fig. 4. 3D map of computed error " $\xi$ " for an AE simulated source (green). Sensor positions (red and pink). (For interpretation of the references to colour in this figure legend, the reader is referred to the web version of this article.)

delay measured between the sensors is influenced by the method of determining the onset time of AE signals. The acquisition of data used in this work has been performed using a FT which is the simplest form for onset picking. This technique defines the onset time of a signal as the time at which the amplitude received by the sensor exceeds a previously established threshold ( $35 \mathrm{~dB}$ here). The disadvantage of this technique is that it is not adapted for signals with small amplitude and high noise level. As presented in Fig. 5 an important delay between the beginning of the signal determined by the FT method and the apparent onset time of the signal is observed.

\subsubsection{Akaike criterion (AIC)}

The onset time detection is determined by comparing the difference between standard deviation passed and forthcoming at each point of the signal. Eq. (4) gives the exact form of this criterion.

$$
A I C_{k}=k \cdot \log [\operatorname{std}(s(1: k))]-(N-k) \cdot \log [\operatorname{std}(s(k: N))] .
$$

where " $\mathrm{k}$ " is the considered sample and " $\mathrm{N}$ " the number of samples where the computation is performed. The orange curve in Fig. 5 shows the complete form of this function. AIC gives the position where there is a significant modification of the signal which, in our case, corresponds to the onset time of AE signal. The minimum of AIC (green) corresponds to the apparent beginning of the signal. Thus, there is no effect of the amplitude in the deamination of the beginning of the signal using the AIC criterion

\subsection{Source localisation techniques}

Analytical solutions do not exist for high order localisation of AE events. In fact, when the number of used sensors is higher than the number of unknown localisation parameters, the system of equations is over-estimated. Computation techniques exist to solve this problem but localisation of only one event means hundreds of calculations. This is why algorithms based on least-squares methods can be used to perform a large amount of process leading to a solution in a short time. Four different algorithms are considered here
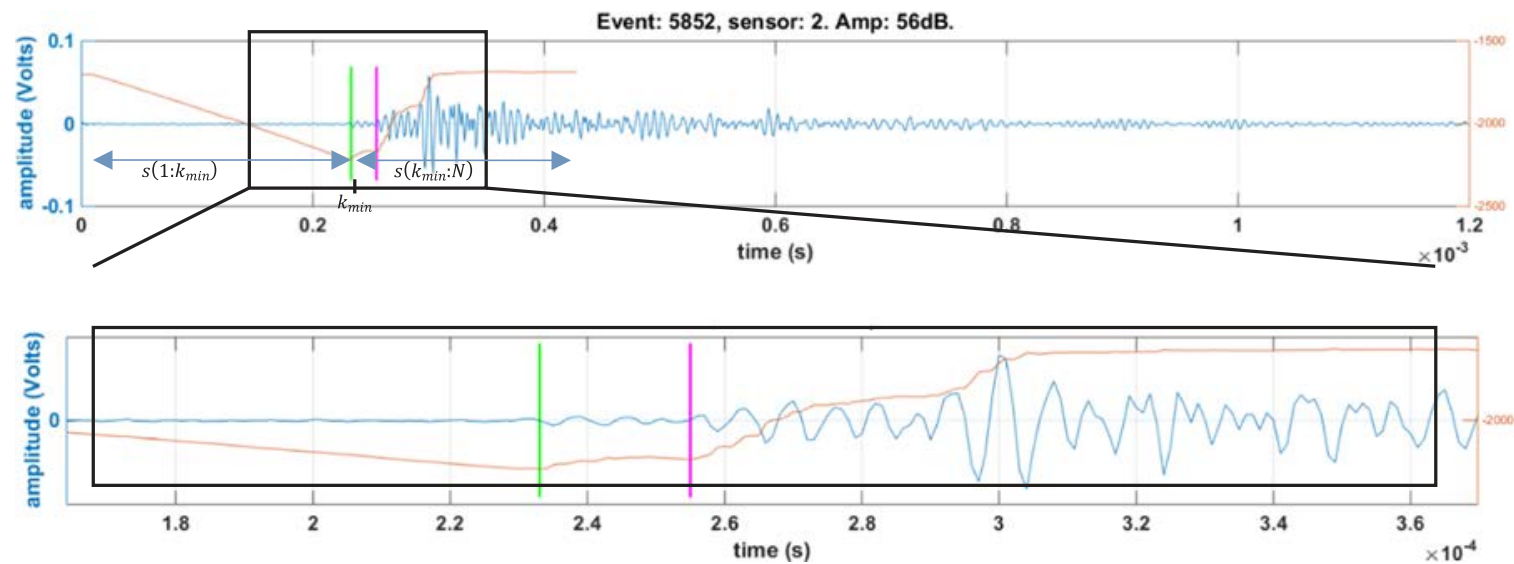

Fig. 5. Typical acoustic waveform and results of two different picking methods: FT (magenta), AIC function (orange) and its minimum (green). (For interpretation of the references to colour in this figure legend, the reader is referred to the web version of this article.) 

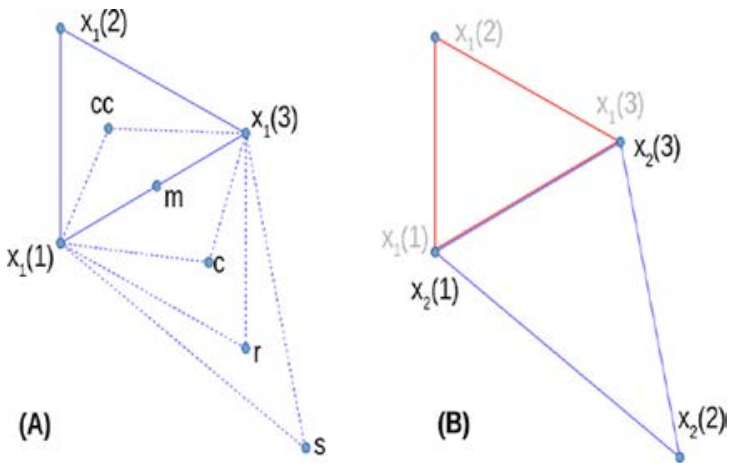

Fig. 6. Example of 2 consecutive simplex in 2D.

in order to find the position $(\mathrm{x}, \mathrm{y}, \mathrm{z})$ of $\mathrm{AE}$ events with a minimum error value.

\subsubsection{Simplex and globalized and bounded Nelder-Mead algorithms (GBNM)}

The simplex algorithm (or Nelder-Mead algorithm) is commonly used in the literature for the localisation of AE sources. The main advantage of this algorithm is its fast computation. However, it requires a starting position, which can greatly affects the results. In addition, if the problem to solve contains local minimums, the algorithm can converge to one of those minimums while only the global minimum is sought. Moreover, in its simplest form (without fixed boundary), the algorithm can converge to a solution corresponding to an event located outside the studied structure. In order to overcome those problems, an enhanced version of the Simplex algorithm called "globalized and bounded Nelder-Mead" is used [50]. Fig. 6 shows an example of simplex process in space with two consecutive simplex in 2D. In this case, the first simplex built from an initial position is a triangle defined by three positions: $x_{1}(1), x_{1}(2)$ and $x_{1}(3)$. Depending on the values of $\xi$ at those points, a new simplex is formed. This new simplex can be reflected ( $\mathrm{r}$ ) extended (s) or contracted outside (c) or inside (cc) version of the first one.

\subsubsection{Genetic algorithm (GA).}

GA are increasingly applied to engineering problems. The global principle of genetic algorithms is to define new solutions by "mutations" or "crossovers" methods. They generate various mathematical solutions using an optimization function [51].

The number of initial solutions, the proportion of solutions retained to build parents, and the way the children are computed from parents are controlled by several parameters that can be modified.

\subsubsection{Adaptive meshing algorithm (AMA)}

In this paper a new adaptive meshing algorithm (AMA) is proposed. The AMA is inspired from the mapping technique [52]. One of the main advantages of AMA compared to other minimisation algorithms is the possibility to easily adapt the shape of meshes used to simulate structures with a more complex geometry than a parallelepiped. The final solution is defined from a set of positions covering the damage referred area. Measured delays $\left(\Delta \mathrm{t}^{\text {meas }}\right)$ between transducers are compared to delays computed at each node of the defined mesh $\left(\Delta \mathrm{t}^{\mathrm{mesh}}\right)$. The comparison between those two set of data is made with the error criterion. To increase the accuracy and reduce the computation time of this technique, three successive meshes are used to determine the position of a single event. Fig. 7 gives an example of the applied set of meshes. The largest mesh (blue) covers almost all the beam, while the second (orange) and third mesh (yellow) cover small areas with closer nodes until $2 \mathrm{~mm}$ of spaced nodes in the case of this study.

\section{Experimental results}

Fig. 8 presents the load versus CMOD curves of three point bending tests for the three tested beams P1, P2, and P3. To get the postpeak branch of the mechanical behaviour, the tests were controlled with a constant crack-mouth opening displacement (CMOD) rate of $2 \mu \mathrm{m} . \mathrm{min}^{-1}$. To better have an idea about the damage level of the tested beams, nine loading-unloading steps were carried out including four steps in the pre-peak phase (at approximately $20 \%, 40 \%, 60 \%$ and $80 \%$ of the maximum load respectively) and three steps in the post-peak phase (at approximately $80 \%, 60 \%$ and $40 \%$ of the maximum load respectively). The loading and unloading phases are spaced by a 20 min stage during which the CMOD is maintained constant. The objective is to evaluate the AE activities which can occur during a stable propagation of the crack, especially in the post-peak phase. Apart from that, three phases in the postpeak branch, namely phase 1 , phase 2 and phase 3, were defined in Fig. 9 corresponding to a stable propagation of the crack from approximately $80 \%, 60 \%$ and $40 \%$ of the maximum load in the post-peak branch respectively.

The slope and the width of the loading-unloading loops can be associated with the damage degree of the beams. The results show a classical behaviour of concrete with an almost elastic phase before reaching the maximum load followed by a nonlinear phase until the failure of the beam. A significant decrease of the slope of the load-CMOD curve in the post-peak phase corresponding to the crack propagation can also be seen from Fig. 8.

The results of mechanical tests are also presented in correlation with the normalized cumulative number of AE events and energy 


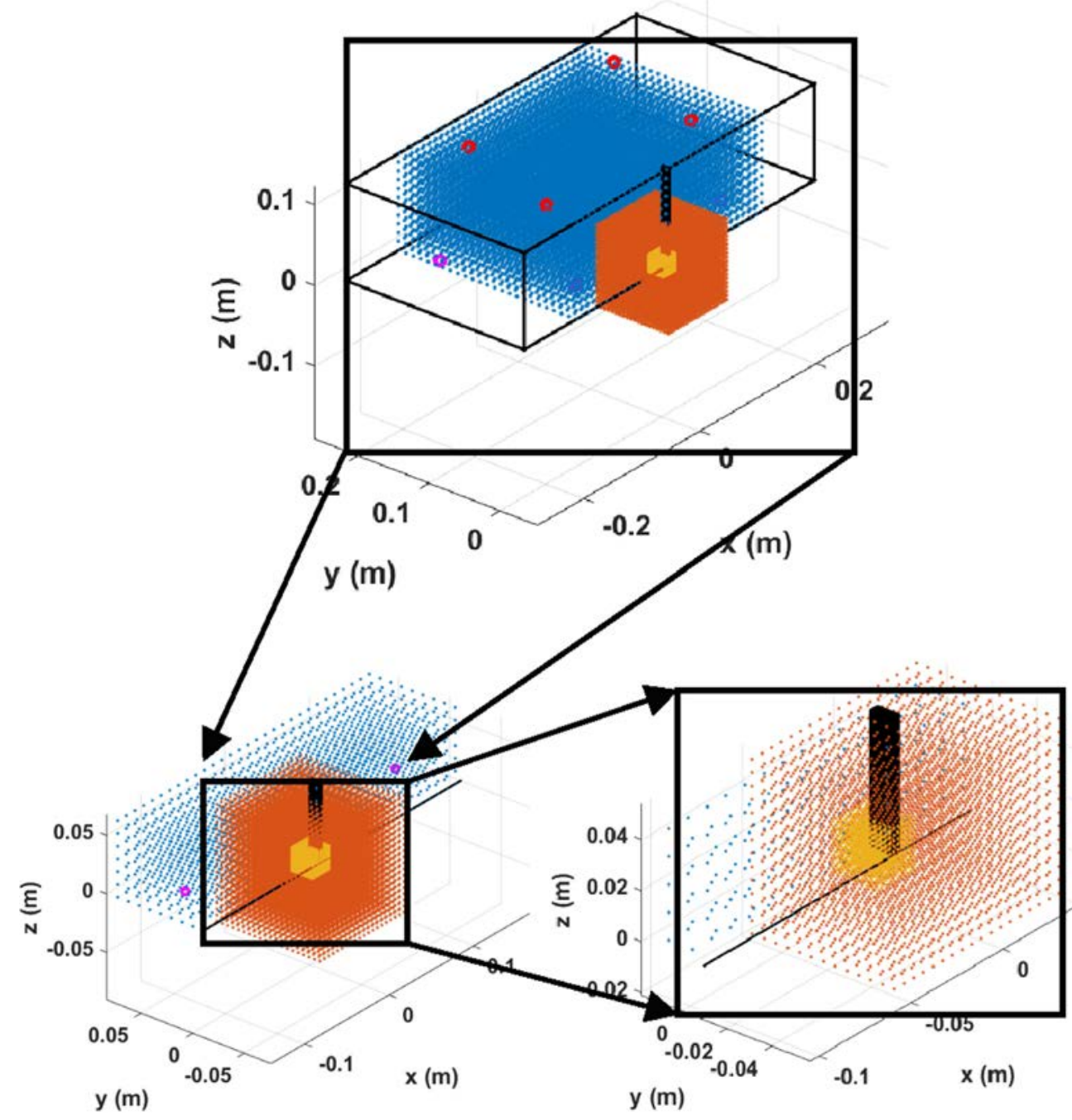

Fig. 7. Example of meshes used in AMA. Coarse mesh $(\sim 1 \mathrm{~cm}$ between blue nodes $)$, first refined mesh $(\sim 0.5 \mathrm{~cm}$ between orange nodes) and final refined mesh ( $\sim 2 \mathrm{~mm}$ between yellow nodes). (For interpretation of the references to colour in this figure legend, the reader is referred to the web version of this article.)

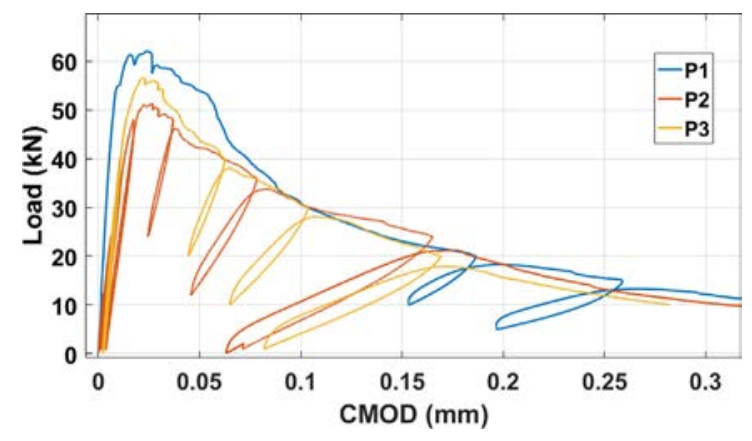

Fig. 8. Load versus CMOD curves for each beam.

as can be seen in Fig. 9. The AE event energy was calculated as the mean value of the corresponding AE hits energy. During the prepeak phase, few AE events are detected. The AE activity grows during the beginning of the nonlinear phase and increases significantly in the post peak region indicating the propagation of the fracture. Finally, AE activity rate decreases progressively and tends to zero for higher CMOD values. Fig. 10 shows the relation between the load proportion and cumulative proportion of events for the three 


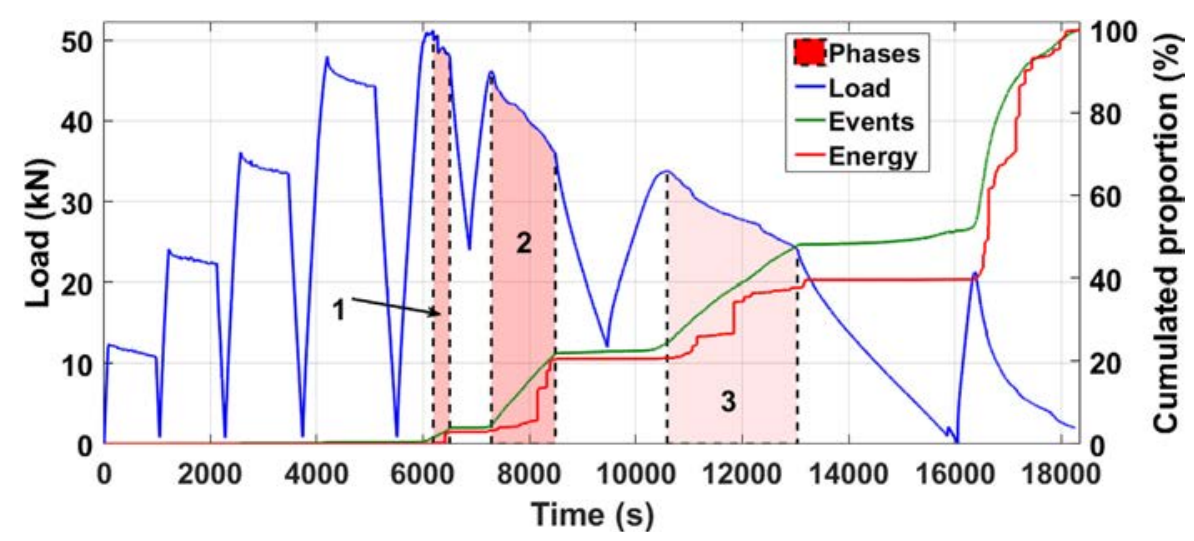

Fig. 9. Load versus time curve correlated to cumulated proportion of events and energy received on P2.

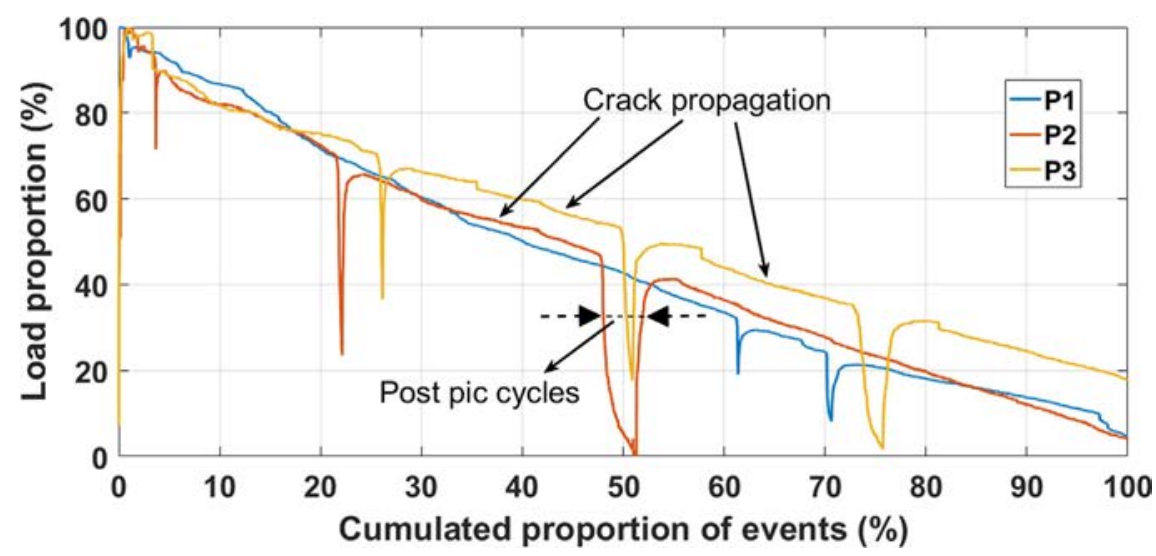

Fig. 10. Relation between load proportion and cumulated events proportion.

tested beams. It can be seen a high correlation between the load proportion and the proportion of events for the three beams with a very close slope. These results indicate that the cumulative proportion of events is a very interesting indicator of concrete damage under bending loading.

\subsection{Influence of onset time detection methods on the localisation of AE events}

Fig. 11 shows the damage localisation maps obtained with the two different onset time detection criteria: fixed threshold FT (a) and Akaike criterion AIC (b). Those maps are the 2D projection of AE events in the main face of the beam. Each blue dot represents one of the detected $\mathrm{AE}$ events. The simplex algorithm has been used in both cases for the minimisation problem. The results show different localisation maps with higher concentration of AE events around the cracking zone when the AIC criterion was used. This can be seen in Fig. 12 showing the distribution of AE events in each direction ( $\mathrm{x}, \mathrm{y}$, and $\mathrm{z}$ ). The distribution is obtained by considering the number of $\mathrm{AE}$ events present at a distance of $1 \mathrm{~cm}$. The results show a clear concentration of AE events around the cracking zone
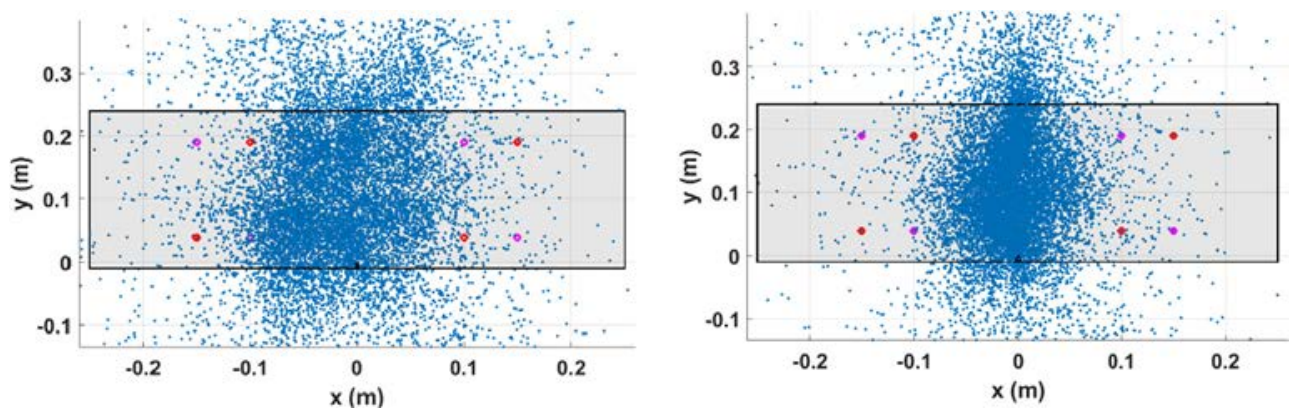

Fig. 11. AE events localisation maps obtained with FT (a) and AIC criterion (b) and Simplex as minimization algorithm. 

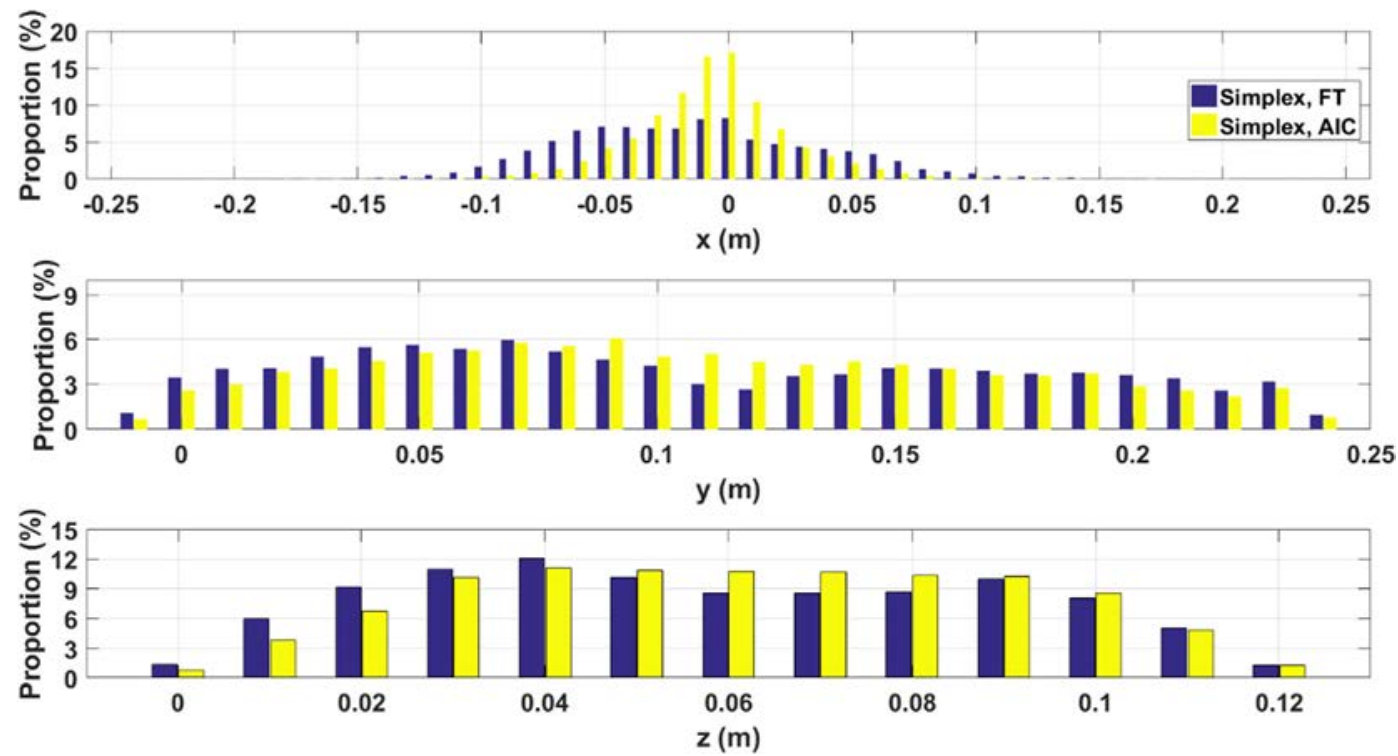

Fig. 12. Comparison of $\mathrm{AE}$ events distribution along $\mathrm{x}, \mathrm{y}$ and $\mathrm{z}$ axis regarding the total number of AE events received for 2 picking methods: AIC (blue) and FT (yellow). (For interpretation of the references to colour in this figure legend, the reader is referred to the web version of this article.)

with $18.7 \%$ above the notch for AIC and $7.5 \%$ for FT regarding the distribution along the $\mathrm{x}$ axis. The width of the FPZ was estimated in previous studies based on the distribution of AE activities considering several criteria [53,54,15]. One of the most used criterions is the one that considers the width of the FPZ as the distance at the intersection between the distribution of AE activities and the line situated at $20 \%$ of the maximum values $[15,16]$. Thus, based on the localisation strategy, the width of the FPZ may vary with an important rate (from $7 \mathrm{~cm}$ with AIC method to $10 \mathrm{~cm}$ with FT method). This indicates that the localisation accuracy should be seriously considered for the characterisation of the damaged zone to avoid misleading results. Another way to compare those two techniques is to evaluate the error (Eq. (3)) obtained with the localisation process in each case. Fig. 13 shows the cumulated number of $\mathrm{AE}$ events located inside the beam in function of the residual error calculated based on Eq. (3). The results show that the proportion of AE events located inside the beam with AIC is systematically higher than the proportion obtained with FT. For example, 40\% of AE events analysed with AIC are located inside the beam with an error less than $2 \mathrm{~cm}$ against only $20 \%$ for AE events analysed with FT. The given proportions are normalized to the total amount of events received during the test in order to make the results comparable.

\subsection{Influence of minimisation algorithms on the localisation of AE events}

Fig. 14 shows the AE events localisation maps obtained when applying GBNM, AMA and GA to solve the minimisation problem. In all the cases and in agreement with the results obtained in the previous Section 4.1, AIC has been applied to determine the beginning

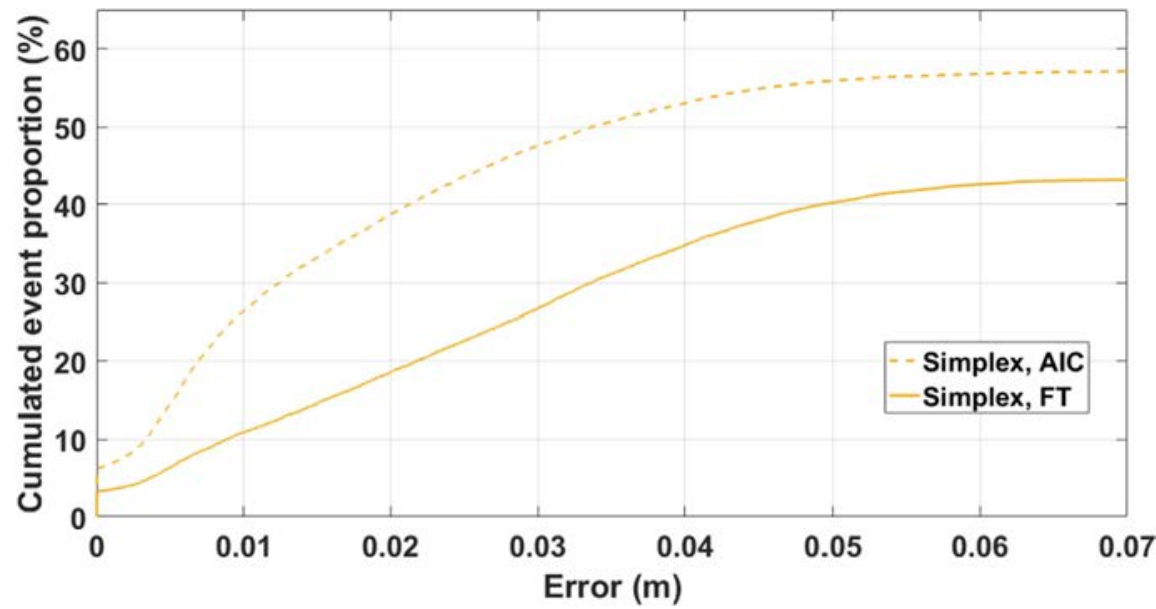

Fig. 13. Proportion of cumulated AE events located inside the beam vs error. Comparison between two criterion for onset time determination of $\mathrm{AE}$ signals: FT and AIC. 

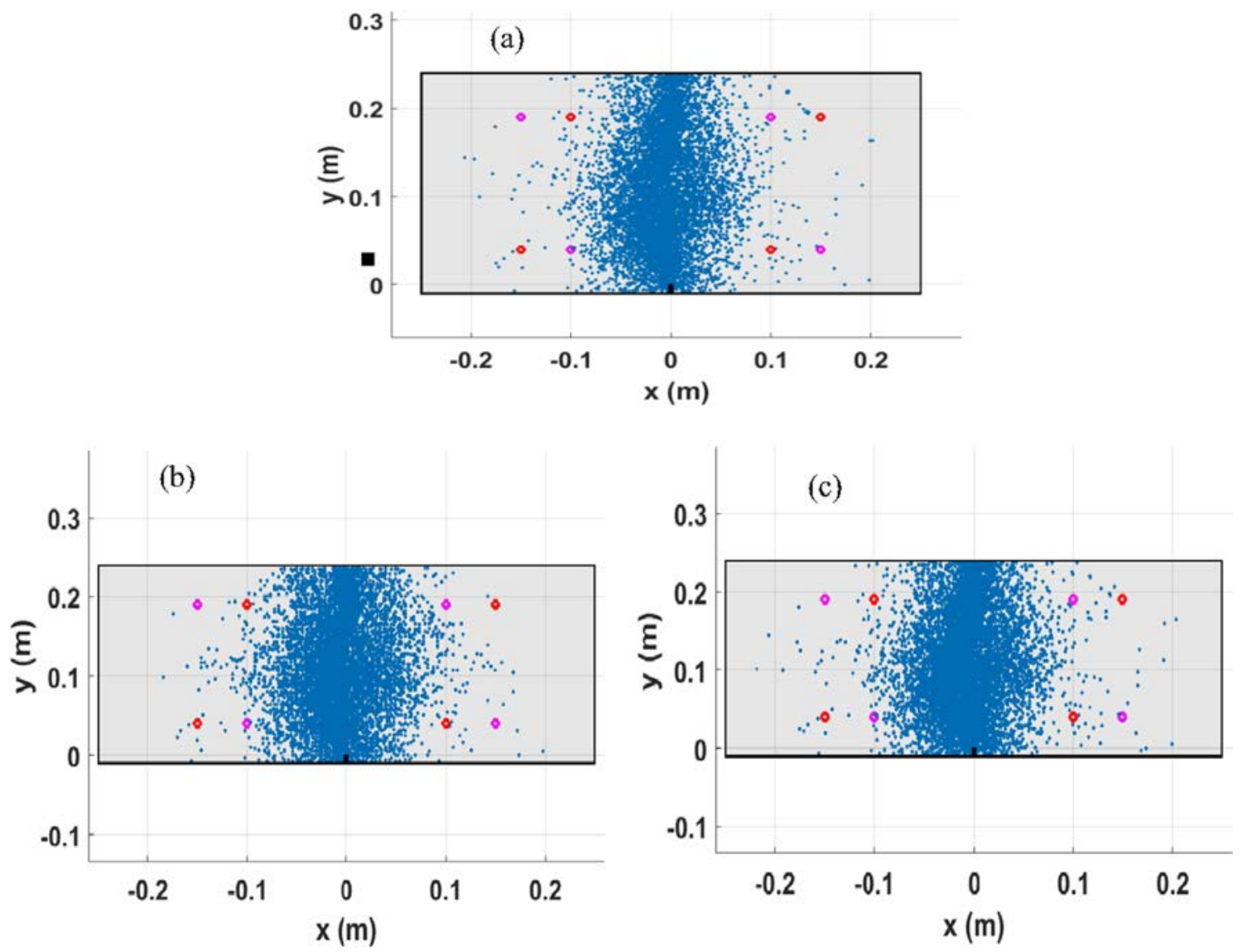

Fig. 14. AE events localisation maps obtained with GBNM (a), AMA (a) and GA (b) with AIC as pick up method.

of signals. At the contrary to simplex algorithm, no AE events are located outside of the beam with GBNM, AMA and GA due to geometrical constraints. The distributions of AE events are similar along the $\mathrm{x}$ axis with $19.8 \%$ of AE events located above the notch with AMA, $18.68 \%$ with GBNM and 19\% with GA.

Fig. 15 shows the cumulative proportion of $\mathrm{AE}$ events located inside the beam in function of the corresponding error. In fact, $\mathrm{AE}$ events localised at the boundary surfaces were also filtered. The results show that the efficiency of algorithms depends on the error range considered. Note here, that the measured error in each algorithm depends on the input parameters. For errors less than $1 \mathrm{~cm}$,

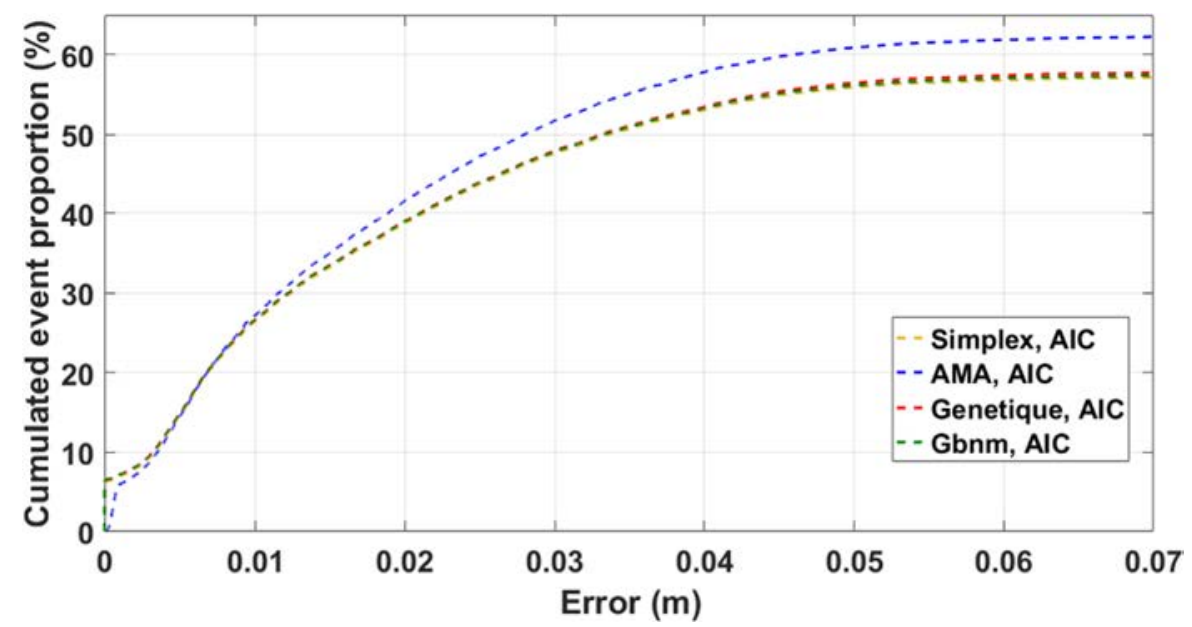

Fig. 15. Proportion of cumulated AE events located inside the beam vs error. Comparison between the four algorithms of resolution: simplex, GBNM, AMA and GA. 


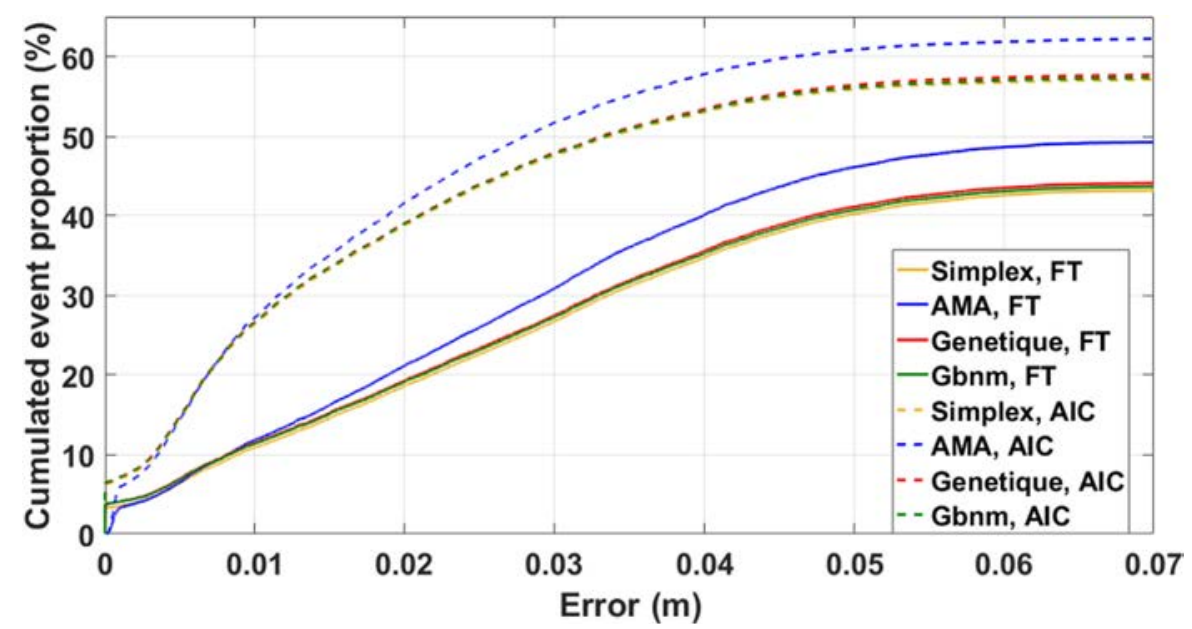

Fig. 16. Proportion of cumulated events inside the beam related to the associated error. Comparison between the different localisation strategies.

AMA, Simplex, GBNM and GA are comparable. However, AMA gives a larger proportion of AE events located inside the beam with an error higher than $1 \mathrm{~cm}$. For example, $44 \%$ of events are located inside the beam with an error less than $2 \mathrm{~cm}$ against $39 \%$ for GA and Simplex algorithm.

\subsection{Global comparison}

Fig. 16 presents the cumulative proportion of $\mathrm{AE}$ events inside the beam in function of the error for each localisation method (onset detection time and source localisation techniques). The amount of events located inside the beam under a given error is higher with the use of AIC criterion for all algorithms. Furthermore, and for a given picking method, the use of AMA algorithm allows a more important proportion of events located inside the beam. However, AMA is less efficient than the two other algorithms for errors less than $1 \mathrm{~cm}$ for both picking method. This is due to the fact that the number of possible final solutions is limited because it depends on the grid defined by the user. If the distance between two nodes of the last mesh is about $2 \mathrm{~mm}$ (which is the case in this study) and the real solution is actually between these two nodes, it will not be possible to find the exact solution. This is why AMA does not perform good results for errors near 0 . The fact that simplex and GBNM and GA allow the location of a larger number of events with error near 0 may be explained by the ability of those algorithms to find the exact solution when the initial position is well defined.

The accuracy of the damaged zone analysis based on AE events can be increased by considering the numerical error as a filter criterion. The amount of the retained data depends on the desired accuracy as well as the localisation strategy based on the minimisation algorithm and the picking method. Thus, this study shows that the localisation of events is more sensitive to the choice of the picking method than the algorithm of minimisation. The four algorithms can be also compared in terms of time consuming. Fig. 17 presents the computation time for each algorithm to determinate the position of one event. The results show that the GA is more time consuming then the three other algorithms.

\subsection{Damage evolution and cracking monitoring}

Based on the previous results, AIC picking method and AMA algorithms have been chosen for the damage and cracking monitoring. Fig. 18 presents the correlation between the load and the cumulative number of AE events and AE energy during the entire loading process in function of time. The density of AE events has been also plotted based on the 2D localisation maps of AE sources at the peak load (Fig. 18a), at 50\% of the maximum strength in the post-peak region (Fig. 18b) and at the end of the test (Fig. 18c). The

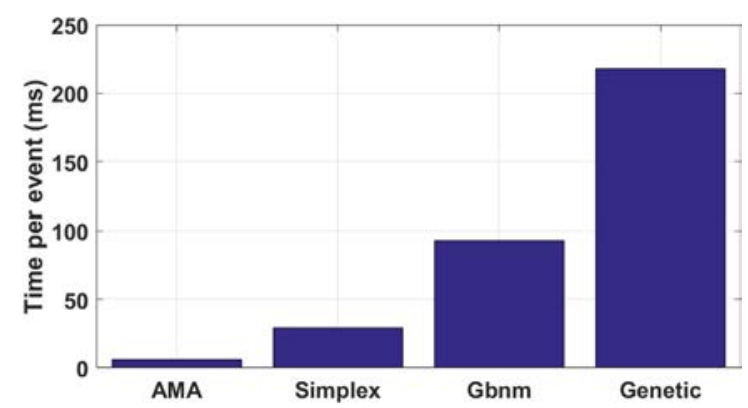

Fig. 17. Mean time consuming by event for each algorithm. 
(a)
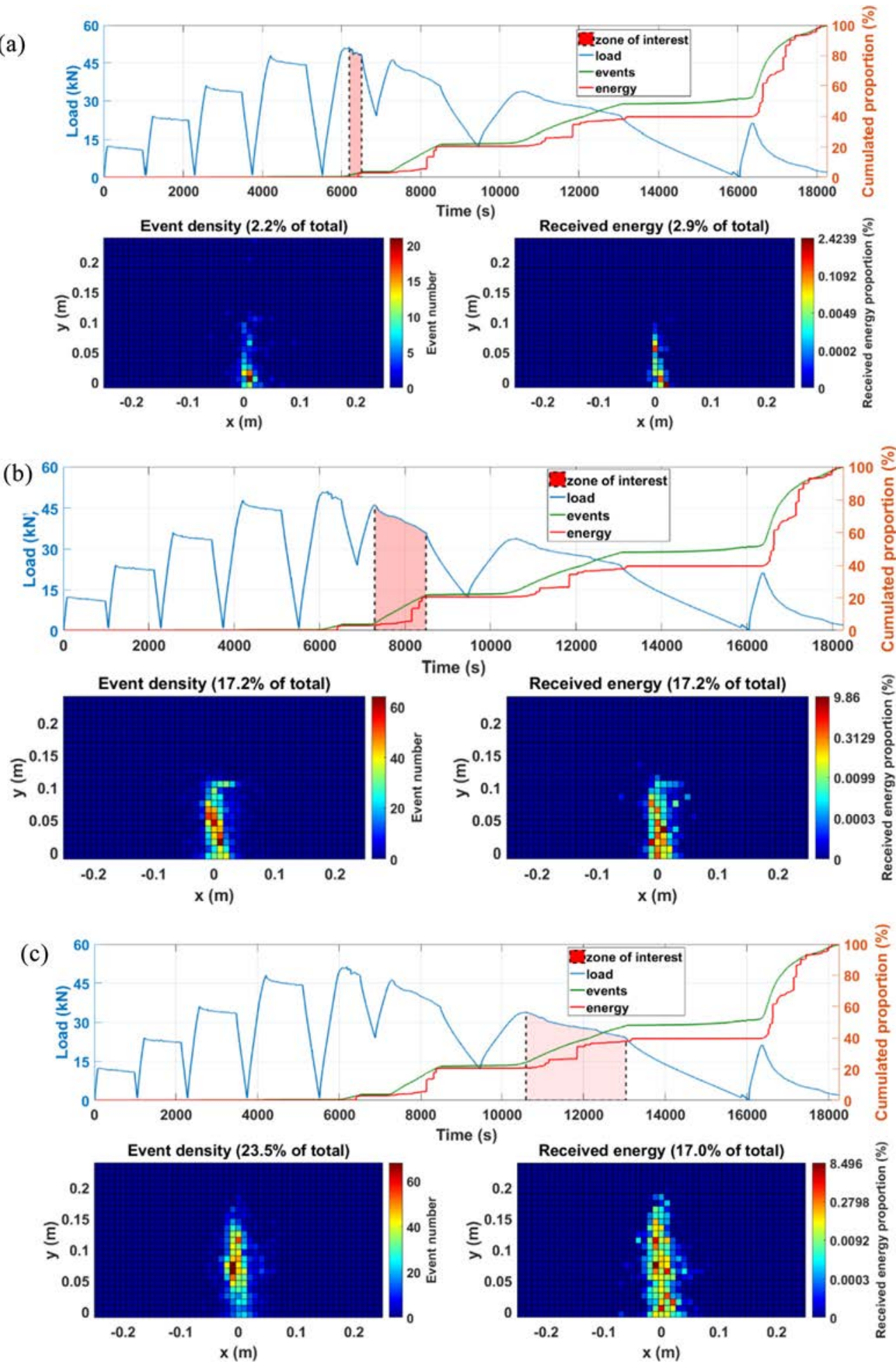

Fig. 18. Correlation between the load and the cumulative number of AE events and AE energy in parallel with the density maps of AE events and AE energy at three different phases of crack propagation.

number of $\mathrm{AE}$ events present in each mesh of $1 \mathrm{~cm}$ is calculated. The $\mathrm{AE}$ events density gives an indication on the areas of acoustic activity in space. The density of $\mathrm{AE}$ events is calculated as the number of localised events in $1 \mathrm{x} 1 \mathrm{~cm}$. In parallel, the density of the absolute acoustic energy has been also plotted as it can provide valuable information on the fracture process. Each event is then 
weighted by the associated energy and normalised with respect to the maximum received energy.

The results from Fig. 18 show that the AE activity (cumulated number of events and energy) is in good correlation with the loading level. The rate of $\mathrm{AE}$ events is low at the beginning and then increases after the load reaches the peak indicating the propagation of the crack. At the peak load, few AE events are detected due to the damage that begins to develop in the nonlinear phase in a distributed manner in front of the notch due to stress concentration.

In the pre-peack phase, no liberation of energy is observed indicating an elastic behavior of the material. After the peak load, the cumulative energy and the number of events increase with two different behaviors (a constant low level of energy followed by a sudden liberation of energy). This behaviour can be related to the typical damage of concrete which is a combination of microdamages (liberation of a low acoustic energy) followed by the propagation of cracks inducing a strong acoustic energy.

The density of AE events and absolute energy (Fig. 18a) also shows that AE events with small energy have been emitted in the first phase (from the beginning of the test until the load-peack. In this phase, the events density and energy density represent only $2.2 \%$ and $2.9 \%$ of the total events and energy, respectively. At $50 \%$ of the peak load in the post peak region, both density of AE events and $\mathrm{AE}$ absolute energy show a more remarkable crack length. In fact, cracks begin to join up together, propagate in the mortar matrix and localise in a single macro-crack exhibiting different realistic features as crack bridging and indicating a rough and complex fracture surface along the ligament length of the beams. During the terminal post peak region, the number of AE events continue to increase with a lower rate due to the stable propagation of the crack. AE events are generated as a consequence of different toughening mechanisms through the crack faces on a micro and meso level, such as bridging and friction. It can be seen that the density of $\mathrm{AE}$ events and $\mathrm{AE}$ energy is higher at the core of the crack outlining the crack path.

\subsection{Combination of DIC and AE techniques for the evaluation of the crack length}

In an attempt to quantify more precisely the propagation length of the crack, that is the position of the crack tip, a new method is proposed based on the comparison between the results obtained by DIC and AE techniques. It consists in determining a criterion based on the cumulative distribution of AE events along the main axis of the crack to identify the crack tip. DIC technique was used to determine the position of the crack tip from surface displacement field measurements. For that, crack opening displacement corresponding to a sudden jump in the displacement field was reported in function of the height of the beam. An example of displacement field obtained after the localisation of a macrocrack is presented in Fig. 20. As can be seen, there is a jump in the displacement field at the position of the crack. Once the crack opening profile was obtained, the crack tip can theoretically be estimated as the position where the crack opening equals to zero [15]. However, one have to note that the crack length obtained by this technique includes not only the length of the (visible) macrocrack but also that of the FPZ where microcracks exist [12]. In this study, the crack tip obtained via the DIC technique was taken as the reference value and is subsequently reported on cumulative AE distributions in order to obtain an estimation of the corresponding value of AE events proportion (Fig. 19).

The crack length measured from the notch tip has been approximately located based on the crack opening profiles as previously explained. The crack length has been measured at different loading stages with DIC and the values were reported on the cumulative local and global distributions of AE events in y direction (Fig. 19). The local distribution consists in considering only events received in a time window corresponding to the interval between two successive measurements. For example, only AE events recorded between 80 and $70 \%$ of the maximum load in the post peak region are considered. However with the global distribution, AE events recorded from the beginning of the test are considered to characterize the length of the crack at a defined time.

The relative position of the crack length $h_{v c}$ obtained by video-correlation is symbolized by a vertical dashed line and the corresponding proportion of AE events can be deduced. The results show that the proportion of AE events located below the hvc height of the crack is systematically greater than $94 \%$ for local distribution and $96 \%$ for global distribution. Thus, the choice of the

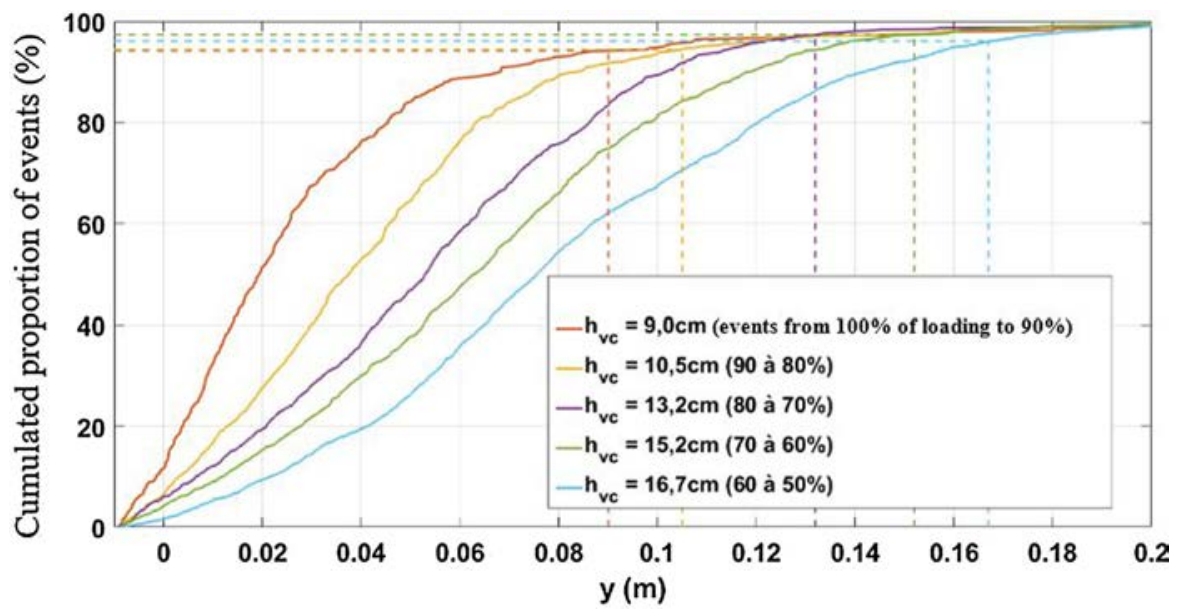

Fig. 19. Cumulative distribution of $\mathrm{AE}$ events in y direction. 


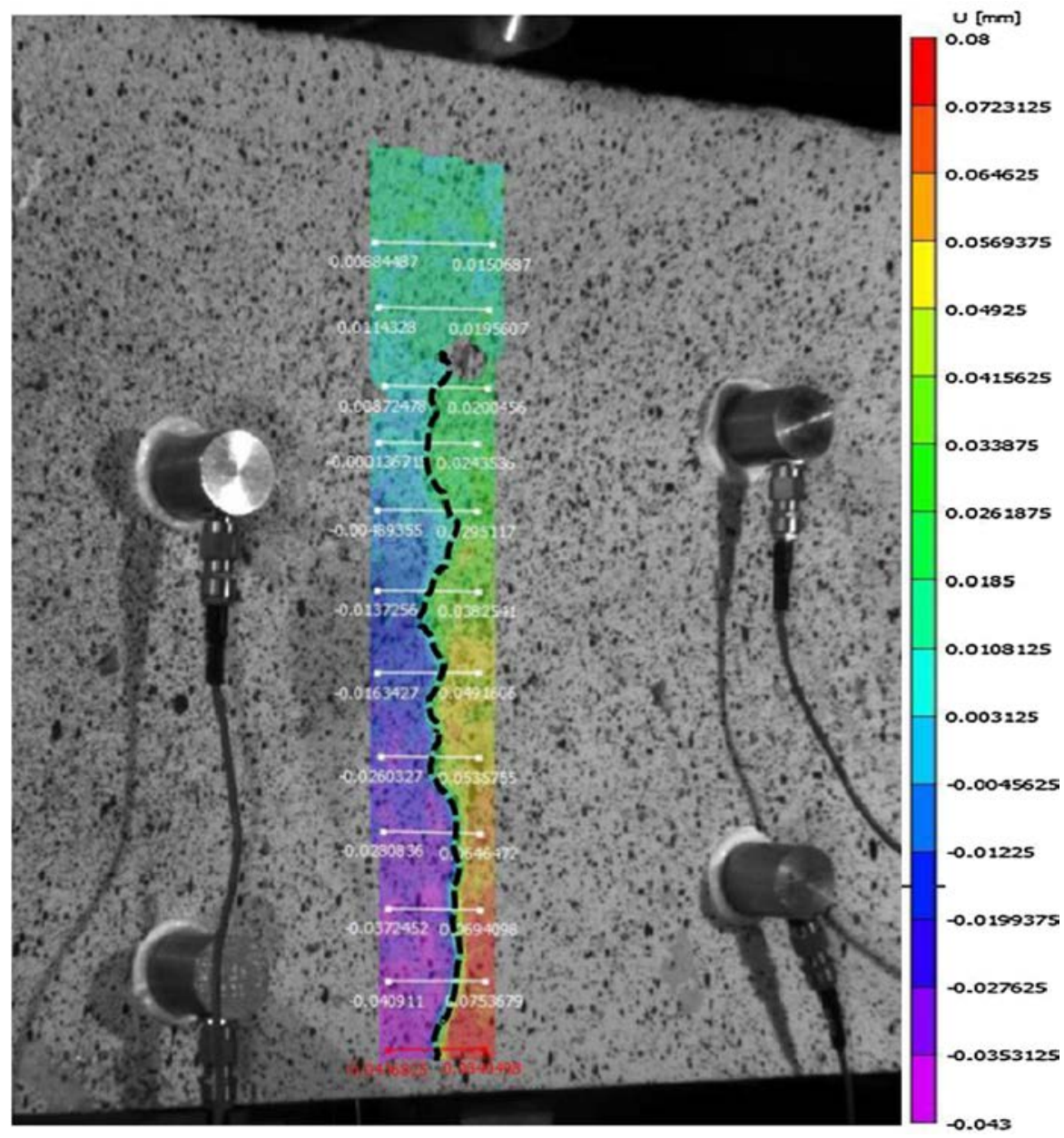

Fig. 20. DIC of cracking in the tested concrete beam.

distribution type does not seem to have an important impact on the discrepancies between both methods. Note here that before the peak, $\mathrm{AE}$ events are spread and the precision of determing the crack length is not very accurate. The comparison between $\mathrm{AE}$ events distributions and DIC measurements allowed to emerge a constant value of about 4-6\% of AE events in front of the notch tip and varies between 2.4 and 7.7\% independently of the used method. Fig. 21 shows the comparison of the crack length obtained with DIC and the local and global distribution of AE events. The results show that the average difference between the crack length measured with DIC and that obtained with both AE distribution methods is almost identical. The use of the global distribution systematically provides a greater height for the crack length in comparison with the local distribution $(0.6 \mathrm{~cm}$ on average). The crack length growth measured using DIC and the cumulative distribution of AE events can be used as an indicator of damage accumulation in the beam. The accuracy of both techniques should be confirmed with other non destructive techniques.

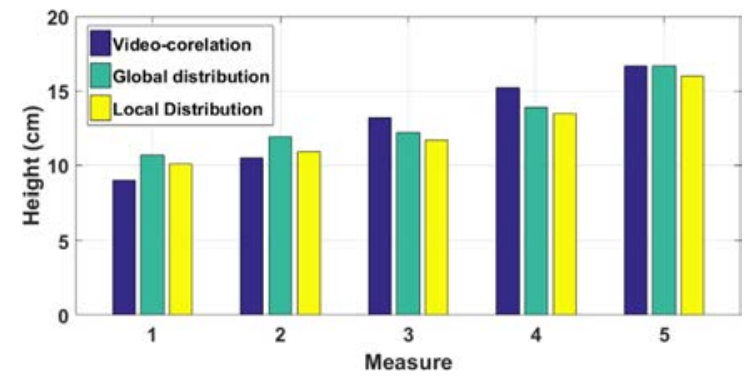

Fig. 21. Comparison of crack length evaluated by DIC and AE. 


\section{Conclusions}

The main objective of this research work was to study the effect of two criteria on the location of AE events. Initially, the influence of the picking methods (AIC and FT) for evaluating the beginning of AE signals has been analysed. Then, the reliability of four localisation algorithms (AMA, GA, GBNM and simplex algorithm) has been studied. The shape of the damage area is greatly affected by the choice of the picking method. The use of AIC leads to a higher distribution of events around the fracture. This can greatly affect the size of the localised damage area. Furthermore, a quantitative comparison between the two criteria shows that the final errors obtained at the end of the localisation process are different. In addition, AIC criterion leads to a higher proportion of events located inside the beam for a given error. On the other hand, no ultimate method has been observed when comparing the four algorithms for solving the optimisation problem: Simplex, GBNM, AMA, and GA. The choice of an algorithm depends on the desired accuracy and the input parameters. In our case, AMA gives better global results for errors larger than $2 \mathrm{~cm}$ which is the chosen limit of the accepted error. Therefore, each algorithm has its own advantages and disadvantages. Another point to consider is the time consuming of each technique. To go further, a mix of the different algorithms could lead to an optimum localisation by dealing with the speed and precision of simplex and the global analysis of GA or AMA techniques. The error of localisation can be considered as a data filtering criteria. The comparison between the DIC and cumulative distribution of AE events shows that a proportion of about $95 \%$ of the events can be used as an indicator to monitor the crack length propagation.

Additional research will be realised in the future in order to improve the localisation accuracy by discriminating effectively AE sources signals for a better monitoring of crack propagation in concrete. Other algorithms are also under test for improving the localisation of events by taking into account the uncertainty of measurements.

\section{Acknowledgements}

This work was conducted as part of the ANR ENDE (Evaluation Non Destructive des Enceintes de confinement) national French project. The National Research Agency is thanked for the financial support as well as all the partners of ENDE project for their valuable contribution.

\section{References}

[1] A. Carpinteri G. Acoustic emission and critical phenomena: from structural mechanics to geophysics. CRC Press book; 2008.

[2] Hadjab H, Thimus J-F, Chabaat M. Fracture process zone in notched concrete beams treated by using acoustic emission, NDT.net. 12; 2004.

[3] Saliba J, Loukili A, Grondin F, Regoin J-P. Identification of damage mechanisms in concrete under creep by the acoustic emission technique. Mater Struct 2014;47:1041-53.

[4] Jankowski LJ. Formation of the fracture process zone in concrete. Eng Fract Mech 1990;36:245-53.

[5] Shah SP. Experimental methods for determining fracture process zone and fracture parameters. Eng Fract Mech 1990;35:3-14.

[6] Sbartaï ZM, Saïdoun K. Evaluation de l'endommagement mécanique des bétons par émission acoustique. Ann Bâtim Trav Publics $2014 ; 66$.

[7] Saliba J, Matallah M, Loukili A, Regoin JP, Grégoire D, Verdon L, et al. Experimental and numerical analysis of crack evolution in concrete through acoustic emission technique and mesoscale modelling. Eng Fract Mech 2016;167:123-37.

[8] Carpinteri A, Lacidogna G, Corrado M, Di Battista E. Cracking and crackling in concrete-like materials: A dynamic energy balance. Eng Fract Mech 2016;155:130-44.

[9] Iturrioz I, Lacidogna G, Carpinteri A. Experimental analysis and truss-like discrete element model simulation of concrete specimens under uniaxial compression. Eng Fract Mech 2013;110:81-98.

[10] Carpinteri A, Lacidogna G, Pugno N. Structural damage diagnosis and life-time assessment by acoustic emission monitoring. Eng Fract Mech 2007;74:273-89.

[11] Maochen G. Analysis of source location algorithms: Part I. Overview and non-iterative methods. J Acoust Emiss 2003;21:21-8.

[12] Maochen G. Analysis of source location algorithms - Part II Iterative methods.pdf. J Acoust Emiss 2003;21:21-8.

[13] Sarout Joël, Ferjani Mohamed, Guéguen Yves. A semi-automatic processing technique for elastic-wave laboratory data. Ultrasonics 2009;49:452-8.

[14] Shehadeh M, Steel JA, Reuben RL. Acoustic emission source location for steel pipe and pipeline applications: the role of arrival time estimation. Proc Inst Mech Eng Part E J Process Mech Eng 2006;220:121-33.

[15] Alam SY, Saliba J, Loukili A. Digital image correlation and acoustic emission: a simultaneous approach for fracture examination in concrete. Constr Build Mater 2014;69:232-42.

[16] Saliba J, Loukili A, Grondin F, Regoin J. Influence of basic creep on cracking of concrete shown by the acoustic emission technique. Mater Struct 2012;45:1389-401.

[17] Stephan G, Kocur GK, Schumacher T, Mhamdi L, Vogel T. A novel multi-segment path analysis based on a heterogeneous velocity model for the localization of acoustic emission sources in complex propagation media. Ultrasonics 2017;74:48-61.

[18] Sokolov IV, Matyunin VM, Barat VA, Chernov DV, Marchenkov AY. Advanced Filtering Methods Application for Sensitivity Enhancement during AE Testing of Operating Structures. Indian J Sci Technol 2016;9(42). https://doi.org/10.17485/ijst/2016/v9i42/104223.

[19] Lamonaca F, Carrozzini A, Grimaldi D, Olivito RS. Improved monitoring of acoustic emissions in concrete structures by multi-triggering and adaptive acquisition time interval. Measurement 2015;59:227-36.

[20] Li J, Qi G. Improving source location accuracy of acoustic emission in complicated structures. J Nondestruct Eval 2009;28:1-8. https://doi.org/10.1007/s10921009-0042-Z.

[21] Jiang Y, Xu F, Xu B. Acoustic Emission tomography based on simultaneous algebraic reconstruction technique to visualize the damage source location in Q235B steel plate. Mech Syst Sig Process 2015;64-65:452-64.

[22] Behnia A, Chai HK, Yorikawa M, Momoki S, Terazawa M, Shiotani T. Integrated non-destructive assessment of concrete structures under flexure by acoustic emission and travel time tomography. Constr Build Mater 2014;67:202-15.

[23] Ciampa F, Meo M. Acoustic emission source localization and velocity determination of the fundamental mode A0 using wavelet analysis and a Newton-based optimization technique. Smart Mater Struct 2010;19:045-027.

[24] Grabowski K, Gawronski M, Baran I, Spychalski W, Staszewski WJ, Uhl T. Time-distance domain transformation for Acoustic Emission source localization in thin metallic plates. Ultrasonics 2016;68:142-9.

[25] Ebrahimkhanlou A, Salamone S. Acoustic emission source localization in thin metallic plates: A single-sensor approach based on multimodal edge reflections. Ultrasonics 2017;78:134-45.

[26] Park WH, Packo P, Kundu T. Acoustic source localization in an anisotropic plate without knowing its material properties - A new approach. Ultrasonics 2017;79:9-17. 
[27] Chen S, Yang C, Wang G, Liu W. Similarity assessment of acoustic emission signals and its application in source localization. Ultrasonics 2017;75:36-45.

[28] Stepanova LN, Ramazanov IS, Kanifadin KV. Estimation of time-of-arrival errors of acoustic-emission signals by the threshold method. Russ J Nondestr Test 2009;45:273-9.

[29] Kurz JH, Grosse CU, Reinhardt H-W. Strategies for reliable automatic onset time picking of acoustic emissions and of ultrasound signals in concrete. Ultrasonics 2005;43:538-46.

[30] Carpinteri A, Xu J, Lacidogna G, Manuello A. Reliable onset time determination and source location of acoustic emissions in concrete structures. Cem Concr Compos 2012;34:529-37.

[31] Schechinger B, Vogel T. Acoustic emission for monitoring a reinforced concrete beam subject to four-point-bending. Constr Build Mater 2007;21:483-90.

[32] Bai F, Gagar D, Foote P, Zhao Y. Comparison of alternatives to amplitude thresholding for onset detection of acoustic emission signals. Mech Syst Sig Process 2017;84:717-30.

[33] Kim J-S, Choi Y-C, Choi J-W, Cho G-C. A combined method of Wigner-Ville distribution with a theoretical model for acoustic emission source location in a dispersive media. KSCE J Civ Eng 2013;17(6):1284-92. https://doi.org/10.1007/s12205-013-0418-6.

[34] Niri ED, Farhidzadeh A, Salamone S. Adaptive multisensor data fusion for acoustic emission source localization in noisy environment. Struct Health Monit $2013 ; 12$.

[35] Sengupta S, Datta AK, Topdar P. Structural damage localisation by acoustic emission technique: A state of the art review. Latin Am J Solids Struct $2015 ; 12: 1565-82$.

[36] Eaton MJ, Pullin R, Holford KM. Towards improved damage location using acoustic emission. Proc Inst Mech Eng Part C J Mech Eng Sci 2012;226(9):2141-53.

[37] Ge M. Source location error analysis and optimization methods. J Rock Mech Geotech Eng 2012;4(1):1-10.

[38] Salinas V, Vargas Y, Ruzzante J, Gaete L. Localization algorithm for acoustic emission. Phys Procedia 2010;3(1):863-71.

[39] Nelder JA, Mead R. A simplex method for function minimization. Comput J 1965;7(4):308-13.

[40] Kurz JH. New approaches for automatic threedimensional source localization of acoustic emissions - Applications to concrete specimens. Ultrasonics 2015;63:155-62.

[41] Linzer L, Mhamdi L, Schumacher T. Application of a moment tensor inversion code developed for mining-induced seismicity to fracture monitoring of civil engineering materials. J Appl Geophys 2015;112:256-67.

[42] Fu T, Zhang Z, Liu Y, Leng J. Development of an artificial neural network for source localization using a fiber optic acoustic emission sensor array. Struct Health Monit 2015;14(2):168-77.

[43] Houck CR, Joines J, Kay MG. A genetic algorithm for function optimization: a Matlab implementation. NCSU-IE TR 1995;95(09).

[44] Scholey JJ, Wilcox PD, Wisnom MR, Friswell MI, Pavier M, Aliha MR. A generic technique for acoustic emission source location. J Acoust Emiss 2009;27:291-8.

[45] Pearson MR, Eaton M, Featherston C, Pullin R, Holford K. Improved acoustic emission source location during fatigue and impact events in metallic and composite structures. Struct Health Monit 2017;16(4):382-99.

[46] A MAM, Orteu J-J, Schreier HW. Introduction. Image Correlation for Shape Motion and Deformation Measurements. US: Springer; 2009. p. 1-12.

[47] Hild F, Roux S, Guerrero N, Marante ME, Flórez-López J. Calibration of constitutive models of steel beams subject to local buckling by using digital image correlation. Eur J Mech A Solids 2011;30(1):1-10.

[48] Lawler JS, Keane DT, Shah SP. Measuring three-dimensional damage in concrete under compression. ACI Mater J 2001;98(6):465-75.

[49] Luo P, Chao Y, Sutton M, Peters W. Accurate measurement of three-dimensional deformations in deformable and rigid bodies using computer vision. Exp Mech $1993 ; 33: 123-32$.

[50] Luersen MA, Le Riche R. Globalized Nelder-Mead method for engineering optimization. Comput Struct 2004;82(23):2251-60.

[51] Haupt, Randy L., Sue Ellen Haupt. Practical genetic algorithms; 2004.

[52] Al-Jumaili SKh, Pearson MR, Holford KM, Eaton MJ, Pullin R. Acoustic emission source location in complex structures using full automatic deltaT mapping technique. Mech Syst Sig Process 2016;2-73:513-24.

[53] Hadjab HS, Thimus JF, Chabaat M. The use of acoustic emission to investigate fracture process zone in notched concrete beams. Curr Sci 2007;93:648-53.

[54] Otsuka K, Date H. Fracture process zone in concrete tension specimen. Eng Fract Mech 2000;65:111-31. 